\title{
Isolation and Identification of Dermatophytes from Clinically Suspected Cases of Dermatophytosis in Patients Attending a Tertiary Care Center Hyderabad
}

\author{
Haseeba Tanveer and S. Pavani* \\ Department of Microbiology, Osmania Medical College, Hyderabad, India \\ *Corresponding author
}

Keywords

Dermatophytes,

Keratinized tissue,

Tricophyton

tonsurans, $\mathrm{KOH}$

Article Info

Accepted:

12 July 2019

Available Online:

10 August 2019

\section{A B S T R A C T}

The dermatophytes are a group of closely related fungi that have the capacity to invade keratinized tissue (skin, hair, and nails) of humans and other animals to produce an infection. The clinical importance of identifying species of dermatophytes is to find out problem source of infection. Moreover, there are some prognostic considerations as well. The study was conducted at the Upgraded department of Microbiology, Osmania general hospital, Hyderabad. About 75 specimens were collected aseptically and were examined under low power and high power objectives of a light Microscope and cultured. Identification is done by tease mount and biochemical reactions. Of the 75, 46 (61.33\%) were positive for both $\mathrm{KOH}$ and culture. Trichophyton tonsurans was the commonest isolate 28/53 (culture positives) (52.9\%). Dermatophytic infections are of concern because of their character of chronicity of the disease. The study highlighted the various types of Dermatophytic infections in and around the places of Hyderabad.

\section{Introduction}

The dermatophytes are a group of closely related fungi that have the capacity to invade keratinized tissue. The etiologic agents of the Dermatophytosis are classified in three anamorphic (asexual or imperfect) genera, Epidermophyton, Microsporum, and Trichophyton, of anamorphic class Hyphomycetes of the Deuteromycota (Fungi Imperfecti). They infect tissue (skin, hair, and nails) of humans and other animals to produce an infection Irene Weitzman et al., 1995. The clinical importance of identifying species of dermatophytes is to find out source of infection. Moreover, there are some prognostic considerations as well.

The present study is aimed at isolation and identification of dermatophyte species. The study was approved by the Institutional ethical committee. 


\section{Materials and Methods}

Study site: Upgraded department of Microbiology, Osmania General Hospital

Study population: 75 clinically suspected cases of Dermatophytosis of all ages and both sexes

Study period: Six Months

Study design: Prospective Study

\section{Collection of skin scrapings}

The scrapings were collected from the edges of the lesions by using sterile blunt scalpel blade after swabbing the lesion with $70 \%$ alcohol. Care was taken not to cause any bleeding from the lesions while collecting the specimens. Scrapings were collected on black photographic paper for better visualization

\section{Collection of nail clippings}

The affected nails were swabbed with $70 \%$ alcohol and Scrapped up to the affected region and also nail clippings were also collected.

\section{Collection of hair plucking}

The affected hairs were epilated using sterile forceps and also scales from the surrounding area were collected after swabbing with $70 \%$ alcohol. Care was taken to include the basal portion of the hair [Hair stub].

\section{Processing}

Small portion of the specimen were transferred aseptically onto a sterile microscopic slide to which a drop of $10 \%$ $\mathrm{KOH}$ (potassium hydroxide) was added and covered with a cover slip. Nail clippings were transferred to a sterile penicillin bottle containing a few drops of $40 \% \mathrm{KOH}$ and kept overnight before examination. Specimens were also examined with a mixture of $\mathrm{KOH}$ and DMSO (dimethyl sulphoxide) as DMSO is a better clearing agent.

All direct positive and negative samples were inoculated on Sabourauds dextrose agar (SDA) containing chloramphenicol and cycloheximide - Himedia and incubated in BOD at $37^{\circ} \mathrm{C}$ and at room temperature. Slants were observed at regular intervals for a period of 6 weeks and absence of growth after the time period was discarded. Any visible growth on the slant was examined for, Colony morphology; a. Topography, b. Texture, c. Surface pigmentation, d. Pigmentation on reverse.

Microscopic morphology was studied by 1 . Lacto phenol Cotton Blue tease mount preparation. 2. Slide culture. Urea hydrolysis done to differentiate T.mentagrophytes.

\section{Results and Discussion}

\section{Clinical types of dermatophytosis}

The study group included 75 clinically suspected cases of Dermatophytosis. The commonest clinical type of Dermatophytosis was Tinea corporis with 33/75(43.6\%) followed by Tinea capitis 17/75 (23.5\%) (Table 1).

\section{Dermatophytosis in relation to age and sex}

Out of 75 cases there were 48 males (63.56\%) and $27(36.44 \%)$. The predominant age group in both males and females was 21-30yrs. (Chart 1)

\section{Results obtained after direct examination} and culture

Out of the total 75 dermatophytosis cases 54 $(71.56 \%)$ were direct $\mathrm{KOH}$ wet mount examination positive and $21(28.4 \%)$ were wet 
mount negative. $46(61.33 \%)$ were positive for both $\mathrm{KOH}$ and culture. $8(10.67 \%)$ were $\mathrm{KOH}$ wet mount positive and culture negative. In 7 (9.2\%) cases culture was positive but $\mathrm{KOH}$ wet mount negative. 14 (18.26\%) were $\mathrm{KOH}$ wet mount as well as culture negative (Table 2).

Incidence of various species of dermatophytes in clinical isolates

Out of the total 75 cases of dermatophytosis 53 were positive for culture. Trichophyton tonsurans 28/53 (52.9\%). was the commonest isolate followed by Trichophyton rubrum 11/53 (21.57\%) (Table 3).

\section{Sites involved}

Out of 75 clinical specimens from the confirmed cases $45(60.03 \%)$ were skin scrapings, $11(14.61 \%)$ were nail clippings and $19(25.33 \%)$ were hair plucking with hair stub (Chart 2). Dermatophytosis is the commonest group of superficial fungal infections seen in the tropics where hot and humid climate is conducive for the growth of the fungi (Siddappa, et al., 1982; Suman Singh, et al., 2003).

This study shown maximum number of cases in the age group of 21-30 years (32\%), followed by 31-40 years (18.22\%), which is in line with Kumar et al., (1990), Banerjee et al., (1987), Amin et al., (1971), Rao et al., (1973) and in contrast with Suman et al., (2003) observed more cases in age group of 11-20 years

The higher incidence in adults aged 20-40 years could be due to greater physical activity with increased sweating and increased opportunity for exposure.

Dermatophytic infection was more common in males 48 (63.56\%) than in females 27 (36.44\%). KM Achary, RK Thakur et al., in 1995(1) reported dermatophytic infection more in men $(65 \%)$ than in women $(35 \%)$.

Table.1 Clinical types of Dermatophytosis

\begin{tabular}{|l|c|c|c|c|}
\hline \multirow{2}{*}{ Clinical types } & \multicolumn{4}{|c|}{ Number of cases } \\
\cline { 2 - 5 } & \multicolumn{3}{|c|}{ Cases(n)=75 } & Percentage \\
\cline { 2 - 5 } Tinea corporis & 33 & 21 & 12 & $43.5 \%$ \\
\hline Tinea capitis & 17 & 12 & 5 & $23.52 \%$ \\
\hline Tinea cruris & 6 & 5 & 1 & $7.56 \%$ \\
\hline Tinea pedis & 6 & 2 & 4 & $7.56 \%$ \\
\hline Tinea unguinum & 5 & 4 & 1 & $6.67 \%$ \\
\hline Tinea mannuum & 4 & 1 & 3 & $5.33 \%$ \\
\hline Tinea barbae & 2 & 2 & 0 & $2.67 \%$ \\
\hline Tinea facei & 1 & 1 & 2 & $2.67 \%$ \\
\hline
\end{tabular}

Table. $2 \mathrm{KOH}$ and culture positivity

\begin{tabular}{|l|l|l|l|}
\hline & KOH POSITIVE & KOH NEGETIVE & TOTAL(n=75) \\
\hline Culture Positive & $46(61.3 \%)$ & $7(9.2 \%)$ & $53(70.6 \%)$ \\
\hline Culture Negative & $8(10.6 \%)$ & $14(18.6 \%)$ & $22(29.4 \%)$ \\
\hline TOTAL $(\mathbf{n = 7 5})$ & 54 & 21 & 75 \\
\hline
\end{tabular}


Table.3 Various species of dermatophytes in clinical isolate

\begin{tabular}{|l|c|c|}
\hline \multirow{2}{*}{ Species } & \multicolumn{2}{|c|}{ Dermatophyte isolated } \\
\cline { 2 - 3 } & No of isolates & Percentage \\
\hline Trichophyton tonsurans & 28 & $52.9 \%$ \\
\hline Trichophyton rubrum & 11 & $21.57 \%$ \\
\hline Trichophyton violaceum & 8 & $14.7 \%$ \\
\hline Trichophyton mentagrophyte & 4 & $6.86 \%$ \\
\hline Trichophyton verrucosum & 2 & $2.94 \%$ \\
\hline
\end{tabular}

Table.4 Comparison of age and sex ratio of dermatophytosis in different studies

\begin{tabular}{|l|c|c|}
\hline & Male: Female ratio & Commonest age group affected \\
\hline Aruna Aggarwal(3) & $1.8: 1$ & $>20 \mathrm{yrs}(60 \%)$ \\
\hline Grover WCS(6) & $4.26: 1$ & $20-30 \mathrm{yrs}(39 \%)$ \\
\hline Parul(11) & $1.75: 1$ & $21-30$ yrs. $(29.3 \%)$ \\
\hline Nawal(9) & $1.8: 1$ & Adult $(66.5 \%)$ \\
\hline V Bindu(5) & $2.06: 1$ & $11-20$ yrs. $(23.3 \%)$ \\
\hline Present study & $1.7: 1$ & $21-30$ yrs.(32\%) \\
\hline
\end{tabular}

Table.5 Comparison of $\mathrm{KOH}$ positivity and culture rate

\begin{tabular}{|l|c|c|c|c|}
\hline & $\begin{array}{c}\text { KOH } \\
\text { positivity } \\
\text { rate }\end{array}$ & $\begin{array}{c}\text { Culture } \\
\text { positivity rate }\end{array}$ & $\begin{array}{c}\text { KOH\& culture } \\
\text { both positive }\end{array}$ & $\begin{array}{c}\text { KOH negative but } \\
\text { culture positive }\end{array}$ \\
\hline Aruna Aggarwal et al., 2002(3) & $59.20 \%$ & $50.40 \%$ & $45.40 \%$ & $1.60 \%$ \\
\hline Grover WCS et al., 2003(6) & $53.30 \%$ & $79.10 \%$ & - & $28.5 \%$ \\
\hline Parul et al., 2010(11) & $62.12 \%$ & $29.29 \%$ & $26.77 \%$ & $2.53 \%$ \\
\hline Nawal et al., 2012(9) & $72.40 \%$ & $62.80 \%$ & - & $7.70 \%$ \\
\hline V Bindu et al., 2002(5) & $64 \%$ & $45.30 \%$ & - & $11.30 \%$ \\
\hline Present study & $\mathbf{6 8 . 1 8 \%}$ & $\mathbf{2 0 . 1 5 \%}$ & $\mathbf{1 5 . 9 1 \%}$ & $\mathbf{4 . 2 0 \%}$ \\
\hline
\end{tabular}

Table.6 Comparison of isolated species

\begin{tabular}{|c|c|c|}
\hline & $\begin{array}{c}\text { Infection involving } \\
\text { multiple sites }\end{array}$ & Commonest species \\
\hline Aruna Agarwal $^{3}$ & $5.06 \%$ & T. rubrum (62.3\%) \\
\hline Grover WCS ${ }^{6}$ & - & T. tonsurans (20.5\%), \\
\hline Parul $^{11}$ & $17.3 \%$ & T. rubrum (54\%), \\
\hline Nawal $^{9}$ & - & T. rubrum (67\%), \\
\hline$V$ Bindu $^{5}$ & - & T. rubrum (66.2\%) \\
\hline $\operatorname{Sen}^{13}$ & - & T. rubrum (68.63\%) \\
\hline Present study & - & T. tonsurans (52.9\%) \\
\hline
\end{tabular}


Chart.1 Dermatophytosis in relation to age and sex

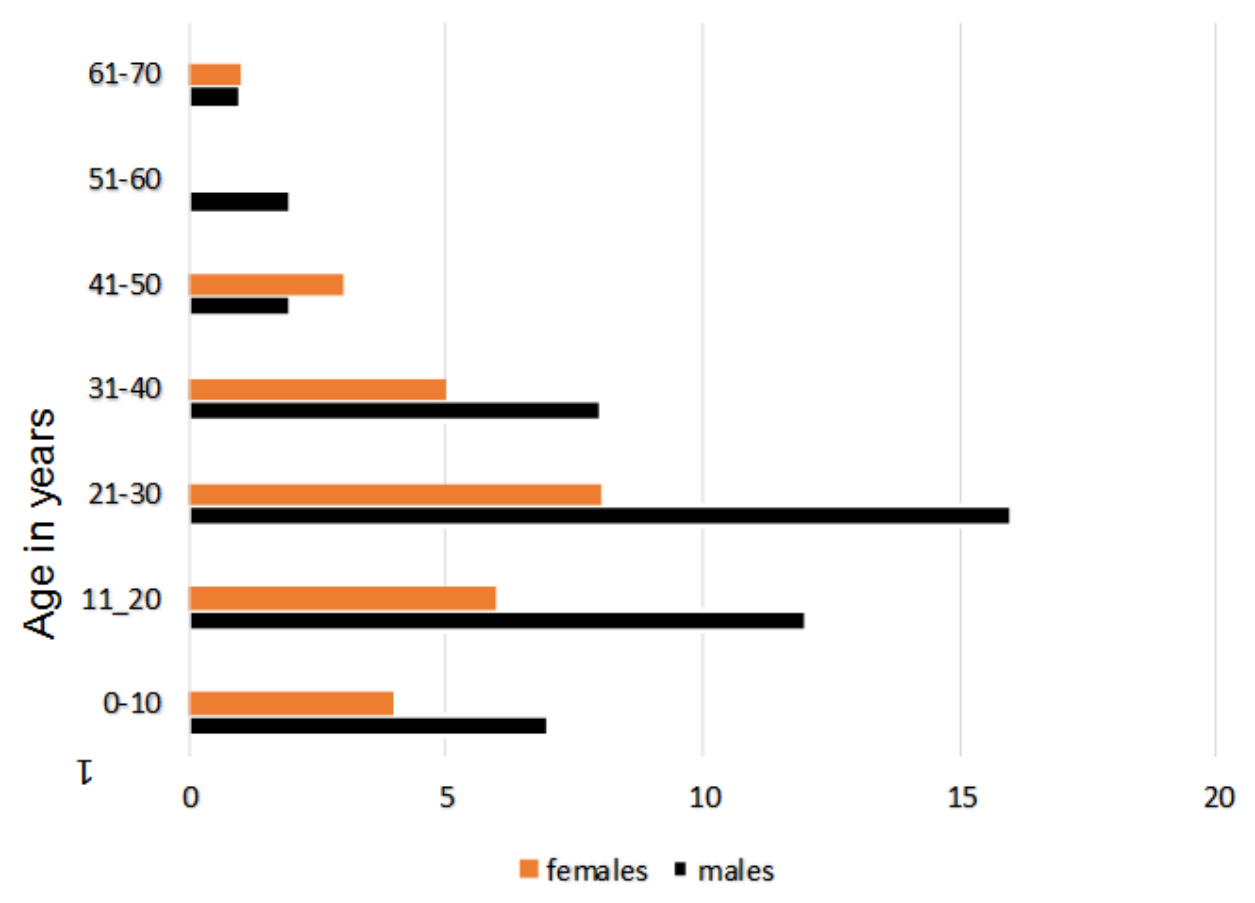

Chart.2 Different sites involved

\title{
sites involved
}

\author{
askin ahair anail
}

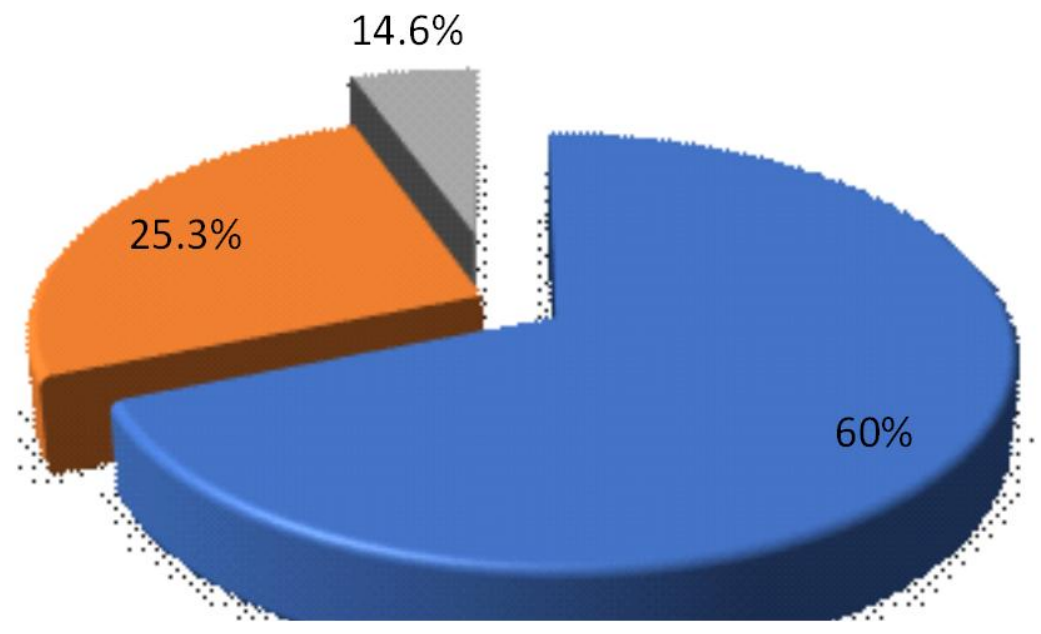


Male predominance of dermatophytosis was observed due to increase outdoor activities and increased opportunity for exposure to the fungi than female. It may also be correlated with the occupational hazards related to their nature of work, the frequent interaction with different people of the society, environmental conditions such as hot and humid weather, poor personal hygiene and illiteracy are other major factors that influence dermatophytosis (Table 4).

The commonest clinical type seen in our study is $\mathrm{T}$. corporis $(43.5 \%)$ followed by $\mathrm{T}$. capitis $(23.5 \%)$ which is also corroborated well with other studies i.e., Suman Sing et al., 2003 64\%, Nawal P et al., 2012 40.8\% (9), Patel P 2010 6\%.

Out of the total 75 Dermatophytosis cases 54 $(71.56 \%)$ were direct $\mathrm{KOH}$ wet mount examination positive and $21(28.4 \%)$ were negative. $46(61.33 \%)$ were positive for both $\mathrm{KOH}$ and culture. $8(10.67 \%)$ were $\mathrm{KOH}$ wet mount positive and culture negative.

In $7(9.2 \%)$ cases culture was positive but $\mathrm{KOH}$ wet mount negative. 14 (18.26\%) were $\mathrm{KOH}$ wet mount as well as culture negative (Table 5).

This shows that $\mathrm{KOH}$ mount with culture is more acuurate than $\mathrm{KOH}$ mount alone

In this study 53/75 cases were culture positive, Trichophyton species have been isolated with increasing frequency as compared to Microsporum and Epidermophyton species

Among them T. tonsurans $(52.9 \%)$ was the predominant isolate followed by $T$ rubrum $(21.5 \%)$ which is in accordance with Grover et al.,(6), and is in contrast to the commonly reported prevalence of dermatophytic fungi in various Indian studies (Table 6).
The findings of this study showed that 3rd decade is most common age group affected with varied duration of symptoms. Tinea corporis was the commonest lesion. Species of Trichophyton namely $T$. Tonsurans was the predominant isolate. Addition of DMSO to $\mathrm{KOH}$ gave better and faster results when compared to plain $\mathrm{KOH}$

Dermatophytosis is a major public health problem and intricately linked with socioeconomic standard of the population. Health education among the population at risk and awareness of preventive measures by following better standards of personal hygiene will help in reducing the prevalence of this disease among the community.

\section{Acknowledgement}

We wish to express our deep sense of gratitude to the technical staff and faculty of Department of Microbiology, Osmania General Hospital for their valuable support and guidance to carry out this study.

\section{References}

Acharya KM, Mukhopadhyay A, Thakur RK, Mehta T, Bhuptani N, Patel R. Itraconazole versus griseofulvine in the treatment of tinea corporis and tinea cruris. Indian J Dermatol Venereol Leprol. 1995; 61: 209-11.

Amin AG, Shah CF, Shjan HS. Analysis of 141 cases of dermatophytosis, Indian J Dermatolo Venereol 1971;31(4): 123128

Aruna Agarwal, Usha Arora, Saroj Khanna: clinical and mycological study of superficial mycoses in Amritsar; Indian J Dermetol 2002 ; 47(4): 218-220

Banerjee U, Pasricha JS. Observation of Tinea corporis in Delhi. Indian J Pathol Microbiol 1987; 207-212. 
Bindu V, Pavithran K. Clinico-Mycological study of dermatophytosis in Calicut. Indian J Dermatol Venereol Leprol 2002; 68: 259-61

Grover WCS, Roy CP. Clinico-mycological Profile of Superficial Mycosis in a Hospital in North-East India. Medical Journal Armed Forces India 2003; 59: 2: 114- 6 .

Irene Weitzman And Richard C. Summerbell The Dermatophytes Clinical Microbiology Reviews, Apr. 1995, p. 240-259 Vol. 8, No. 2 08938512/95/\$04.0010 Copyright q 1995, American Society for Microbiology

Kumar AG, Lakshmi N. Tinea capitis in Tirupathi. Indian $\mathrm{J}$ Pathol microbial 1990; 33(4): 360-363.

Nawal P, Patel S, Patel M, Soni S, Khandelwal N. A Study of Superficial Mycosis in Tertiary Care Hospital. NJIRM 2012; 3(1): 95-99
Patel P, Mulla S, Patel D, Shrimali G.A Study of Superficial Mycosis in South Gujarat Region. National Journal of Community Medicine 2010, Vol. 1, Issue 265

Parul Patel, Summaiya Mulla, Disha Patel, Gaurishankar Shrimali; a study of superficial mycosis in south gujarat region, National Journal of Community Medicine 2010, Vol. 1, Issue 2

Rao BR, Annapurna E. Dermatophytosis in Vishakapatnam. Indian J Dermatology Venereol 1973; 39(5): 209-212.

SS Sen, ES Rasul; Dermatophytosis in Assam; 2006. 24(1): 77-78

Suman Singh, Beena PM. Profile of Dermatophyte infections in Baroda. Indian J Dermatol Venereol Leprol 2003; 69: 281-283.

Siddappa K, Mahipal OA. Dermatophytosis in Davangere. Indian J Dermatol Venereol Leprol. 1982; 48(5): 254-9. 7.

\section{How to cite this article:}

Haseeba Tanveer and Pavani, S. 2019. Isolation and Identification of Dermatophytes from Clinically Suspected Cases of Der-matophytosis in Patients Attending a Tertiary Care Center Hyderabad. Int.J.Curr.Microbiol.App.Sci. 8(08): 1503-1509. doi: https://doi.org/10.20546/ijcmas.2019.808.176 